\title{
Coagulase - Positive Staphylococci Isolated from Cattle in Maiduguri, Nigeria
}

\author{
Martha Echioda-Ogbole ${ }^{1 *}$, James A. Yaza ${ }^{2}$, James A. Ameh ${ }^{1}$, Samuel Mailafia ${ }^{1}$, \\ Olatunde H. Olabode ${ }^{1}$, Bridget J. Adah ${ }^{1}$, Godspower R. Okoh ${ }^{1}$ and Stella Maduike ${ }^{1}$ \\ ${ }^{I}$ Department of Veterinary Microbiology, Faculty of Veterinary Medicine, \\ University of Abuja, Nigeria \\ ${ }^{2}$ Department of Veterinary Microbiology, Faculty of Veterinary Medicine, \\ University of Maiduguri, Nigeria
}

*Corresponding author

\begin{abstract}
A B S T R A C T
Staphylococci are Gram positive bacteria capable of causing both localize and lifethreatening systemic infections in animals and humans. The present study was aimed at the isolation and identification of various Staphylococci species from cattle in Maiduguri

Keywords

Staphylococci species, Coagulase, cattle,

Antimicrobial testing, Maiduguri

Article Info

Accepted: 12 April 2018 Available Online: 10 May 2018 Borno State. One hundred (100) nasal swabs were randomly collected from cattle in January 2011, and then processed in accordance with standard methods for bacteria isolation. Colony morphology, assessment on manitol salt agar (MSA), coagulase, catalase and haemolytic tests were among the standard bacteriological methods used in the identification and biochemical characterization of Staphylococci species. Isolates were then subjected to an in-vitro antimicrobial susceptibility testing using the disc diffusion method. 92 bacterial isolates were obtained, 21 of the isolates were identified as coagulasepositive Staphylococcus aureus, 49 as coagulase - negative Staphylococci, while 22 isolates were identified as micrococci. All the Staphylococcus aureus isolates were positive for mannitol fermentation test and produced beta- heamolysis on blood agar containing 5\% sheep erythrocytes. Staphylococci species were most susceptible to ciprofloxacin $(100 \%)$ and ceftrazole $(90.5 \%)$. In conclusion, this study indicates the occurrence of coagulase positive and negative Staphylococci in Bovine nasal mucosa in the study area thus suggest ciprofloxacin and ceftrazole as drug of choice in the treatment of infections and diseases caused by staphylococcus.
\end{abstract}

\section{Introduction}

One of the most important phenotypical features in the classification of Staphylococci is their ability to produce coagulase, an enzyme -like protein that clots oxalated or citrated plasma (Ryan and Ray, 2004). Under the family Staphylococcaceae, Genus
Staphylococcus is mainly classified as coagulase - positive and coagulase - negative Staphylococci. Coagulase may deposit fibrin on the surface of Staphylococci, thereby preventing their digestion by phagocytic cells or their destruction within such cells. Its production has traditionally been used to differentiate Staphylococcus aureus from 
coagulase - negative Staphylococci and is considered synonymous with invasive pathogenic potentials (Jin et al., 2004).

Recent taxonomic studies have shown that the genius Staphylococcus can be divided into at least 40 species and 17 subspecies, seven species are currently recognised as being coagulase- positive (Jin et al., 2004). Staphylococci grow easily on many types of laboratory media, fermenting carbohydrates and producing pigments that vary from white to golden yellow. Some are members of the normal microfloral of the skin and mucous membranes of humans and animals, whereas others cause suppuration, abscess formation, pyogenic infections and even life threatening septiceamia (Karen, 2013).

Pathogenic Staphylococci species often hemolyze blood, coagulate plasma and produce a variety of extracellular toxins and enzymes (Nwankwo and Nasiru 2011). In routine diagnostic microbiology, the major pathogenic Staphylococcal species Staphylococcus aureus (S. aureus) can be differentiated from other species by means of a single test, coagulase or clumping-factor production (Carter et al., 2003). The production of coagulase as an enzyme, fermentation of mannitol and glucose and testing for the presence and types of hemolysis on blood agar plates distinguish Staphylococcus aureus primarily from other Staphylococci (Carter et al., 2003). Additional diagnostic procedures requires to confirm $S$. aureus colonies includes microscopic examination following Gram staining and other biochemical tests such as catalase, anaerobic utilization of glucose, anaerobic utilization of mannitol, lysostaphin sensitivity and production of thermostable nuclease (TNase) as well as application of the ready to use identification kits, such as the APi- Staph system (bioMerieux, France) (Silva et al., 2000). The aim of the present study was to report the occurrence, biochemical characteristics and antimicrobial profile of Staphylococci isolates from Bovine nasal swab in Maiduguri.

\section{Materials and Methods}

\section{Study location}

Maiduguri is located in the arid zone of Borno State covering an area of about $69,436 \mathrm{~km} 2$ and is situated within latitude $11^{\circ} 50^{\prime} 46^{\prime \prime} \mathrm{N}$ and longitude $13^{\circ} 08^{\prime} 29^{\prime}$ E. It is in the subSaharan region with low records of rainfall. The area is in the tropical continental north with dry period of 4-8 months usually October to May, and a short rainy season which starts from June to early October. The state is located in the North Eastern corner of Nigeria and shares common boundaries with Cameroon to the East, Chad to the North East and Adamawa State to the South West. According to the 2005 census, the population is estimated to be 4,558,668 and ranked 12th in the country. Agriculture and livestock husbandry forms the mainstay of the state economy (World Gazetteer, 2007).

\section{Sample collection and bacterial isolation}

One hundred (100) nasal swabs were randomly collected from cattle at University of Maiduguri teaching and research farm and immediately transported in a cool thermos to the Veterinary Microbiology Laboratory, University of Maiduguri and processed within 24hour.

Staphylococci were isolated in accordance with standard methods as described by Collee et al., (1989). The swabs were directly inoculated onto prepared plates of mannitol salt agar (Oxiod), and then incubated at $37^{\circ} \mathrm{C}$ for 24hours. Following incubation, all plates were examined for colonial morphology and pigmentation, and then recorded for each 
different Staphylococci isolates. Representative colony of each presumptive Staphylococci isolate type per specimen was picked with a sterile wire loop and transferred onto slants of nutrient agar and incubated overnight at $37^{\circ} \mathrm{C}$, stored at $4{ }^{\circ} \mathrm{C}$ for further biochemical characterization and antimicrobial susceptibility testing.

\section{Staphylococci identification}

Various Staphylococci species were confirmed phenotypically on the basis of colony morphology assessment, Gram staining and microscopic appearance, anaerobic acid production from glucose, clumping factor and were tested for oxidase, catalase and coagulase production according to Lancette and tatini (1992). In addition, haemolytic properties of Staphylococcal isolates were studied on blood agar containing 5\% sheep blood as described by Cheesbroug (1989).

\section{Antibiotic susceptibility testing}

The susceptibility testing of isolates to ten (10) antibiotics was carried out using the disk diffusion method according to the Clinical Laboratory Standard Institute guidelines (CLSI, 2006). The antibiotic (Poly-Test Medical Laboratories) included ofloxacin $(5 \mu \mathrm{g})$, erythromycin $(10 \mu \mathrm{g})$, ciprofloxacin $(5 \mu \mathrm{g})$, clindamycin $(10 \mu \mathrm{g})$, gentamycin $(10 \mu \mathrm{g})$, cephalexin $(30 \mu \mathrm{g})$, cotrimoxazole $(50 \mu \mathrm{g})$, ampicillin $(30 \mu \mathrm{g})$, ceftriaxone $(5 \mu \mathrm{g})$

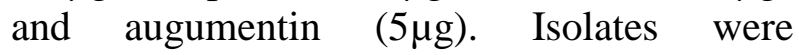
inoculated unto prepared nutrient agar plates and allowed to dry for 2-5 minute after streaking; sterile forcep was used to place the antibiotic multi- discs on the inoculated plates and then incubated at $37^{\circ} \mathrm{C}$ for $24 \mathrm{~h}$. Zones of bacteria inhibition were measured to the nearest millimetre using a ruler and interpreted as susceptible, intermediate and resistant as indicated by the Clinical and Laboratory Standards Institute guidelines (CLSI, 2006).

\section{Results and Discussion}

A total of 92 bacterial isolates of different species were isolated from one hundred (100) cattle in this study. Of these, 21 isolates were confirmed phenotypically as Staphylococcus aureus, all the $S$. aureus strains were positive for coagulase test, with vary degree of reactions ranging from $2+, 3+$ and $4+$. Forty nine (49) Staphylococcal isolate were found to be coagulase negative Staphylococci (CoNS), while 22 bacteria isolates were identified as Micrococci species.

The coagulase gene has been a target for PCR genotyping where size and DNA restriction endonuclease site polymorphism within the coa gene is been use for PCR-RELP analysis (Hookey et al., 1998). Generally, molecular typing of Staphylococcus aureus has been reported as most preferred method for most clinical laboratories because of its ease, speed and a precise result (Montesinos et al., 2000). However, this is not within the scope of our study. Hence, the limitation of this study was the inability to subject isolates to molecular work such as PCR genotyping of coa gene of the isolated strains of Staphylococcus aureus, thus recommend for future work.

The 21 coagulase positive Staphylococcus aureus (CoPS) were positive for mannitol fermentation and coagulase tests, and produces $\beta$ haemolysis on blood agar which contained sheep erythrocytes. Whereas the 49 coagulase negative Staphylococci (CoNS) were found negative for the above tests. This finding is in line with report of Arshad et al., (2006), who collaborate production of coagulase, DNAase and the fermentation of mannitol as important characteristics of Staphylococcus aureus. In clinical microbiology, the production of coagulase a major virulence factor is the principal criterion used in the diagnosis of strains of Staphylococcus aureus (Carter et al., 2003). 
So far, S. aureus remains the most important pathogenic species of Staphylococcus, it is an organism physicians should be buddy with.

The occurrence of CoNS in this study was higher (53\%) than CoPS. This finding could be attributed to the fact that CoNS are part of the normal microbiota of the body with striking predilection for skin and mucous membranes and are generally considered to be of low virulence. However, sometimes they can cause infections often associated with implanted devices, such as joint prostheses, shunts and intravascular catheters by colonizing theses biomaterials, especially in very young, old and immunocompromised patients (Karen, 2013).

CoNS have also established themselves as important pathogens showing increasing trends towards antibiotics resistance in the last decade (Smolinski et al., 2003).

Table.1 Cultural and biochemical characteristics of Staphylococci and Micrococci isolated from cattle in Maiduguri

\begin{tabular}{|c|c|c|c|c|c|c|c|}
\hline Growth on MSA & Colony colo & a sta & ag & Catala & $\mathrm{mol}$ & Isolates & No \\
\hline+ & yellow & + & + & + & + & S. aureus & 21 \\
\hline+ & pink & + & - & + & _ & CoNS & 49 \\
\hline+ & yellow & + & - & + & _. & Micrococs & i 22 \\
\hline
\end{tabular}

Table.2 In - vitro antibiotic susceptibility testing of Staphylococcus aureus isolated from cattle in Maiduguri $n=21$

\begin{tabular}{lll}
\hline Antibiotic & No susceptible (\%) & Resistant (\%) \\
\hline Ciprofloxacin & $21(100)$ & $0(0)$ \\
Gentamycin & $6(28.6)$ & $15(71.4)$ \\
Ceftriaxone & $19(90.5)$ & $2(9.5)$ \\
Cotrimoxazole & $15(71.4)$ & $6(28.6)$ \\
Ampicillin & $7(33.3)$ & $14(66.7)$ \\
Clindamycin & $16(76.2)$ & $5(23.8)$ \\
Augumentin & $17(81.0)$ & $4(19.0)$ \\
Ofloxacin & $13(61.9)$ & $8(38.1)$ \\
Cephalexin & $3(14.3)$ & $18(85.7)$
\end{tabular}


Biochemically, Staphylococci isolates were catalase and citrate positive, oxidase negative, strains of $S$. aureus were coagulase positive, whereas other Staphylococci isolates were negative table 1 . The production of catalase, an enzyme which breaks down hydrogen peroxide to water and oxygen by Staphylococci distinguished them from Streptococci.

Result of antibiotic susceptibility testing did show that Staphylococcus aureus species were susceptible to ciprofloxacin (100\%), ceftriaxone $(90.5 \%)$, augumentin $(81 \%)$ and clindamycin $(76.2 \%)$. Our study observed a high percentage of cephalexin resistance $(85.7 \%)$ and gentamycin $(71.4 \%)$ to Staphylococci isolates as shown in table 2.

In this study, there was complete (100\%) susceptibility of Staphylococcus aureus species to ciprofloxacin. This result collaborate the reports of Nwankwo and Nasiru (2011) that reported high level of susceptibility of Staphylococci to ciprofloxacine and showed that the flouroquinlones are effective in the treatment of Staphylococcus aureus infections including Methicillin resistant strains in Kano, North West Nigeria.

The high sensitivity of Staphylococcus aureus to these drugs could be attributed to the fact that the quinolones are new generation antibiotics and have not been abuse. In conclusion, this study reports the occurrence of coagulase positive Staphylococcus aureus from apparently healthy cattle in the study area and recommends ciprofloxacin and ceftriaxone as drugs of choice for the treatment of Staphylococcal infections.

\section{Conflict of interest}

All authors hereby declare that they have no conflict of interest

\section{Acknowledgement}

Authors are grateful to the management and staffs of University of Maiduguri animal farm for their support and assistance during sample collection. Special thanks to $\mathrm{Mr}$ Samson Onyilokwo of Veterinary Microbiology Laboratory University of Maiduguri for his technical assistant.

\section{References}

Arshad, M., Muhammad, G., Siddique, M., Ashraf, M. and Khan, H. A. (2006). Staphylococcal Mastitis in Bovines and some properties of Stahylococcal isolates. Pakistan Veterinary Journal, 26(1): 20-22.

Carter, P.E., Begbie, K. And ThomsonCarter, F.M. (2003). Coagulase gene variants associated with distinct populations of Staphylococcus aureus. Journal of Epidemiological Infections, 130: $207-219$.

Cheesbrough, M. (1989). Medical Laboratory Manual for Tropical Countries, Vol. 11. ELBS, London, UK.

Clinical Laboratory Standard Istitute Guidlines (CLSI) (2006). Performance standards for antimicrobial disk susceptibility tests. NCCLS document M2-A8, Wayne, PA-NCCLS.

Collee, J.G., Duguid, J.P., Fraser, A.G. and Marmion, B. P (1989). Mackie and McCartney Practical Medical Microbiology, Vol. 2. $13^{\text {th }}$ Edition. Curchchill, Livingstone, Edinburgh, UK.

Hookey, V., Richardson, J.F. and Cookson, B.D. (1998). Molecular typing of Staphylococcus aureus based on PCR restriction fragment length polymorphism and DNA sequence analysis of the coagulase gene. Journal of Clinical Microbiology, 36:10831089. 
Jin, M., Rosario, W., Watler, E. and Calhoun, D.H. (2004). "Development of a largescale HPLC-based purification for the urease from Staphylococcus leei and determination of subunit structure" (PDF). Protein Expr. Purif. 34 (1): 111117. doi:10.1016/j.pep.2003.10.012.

Karen, C. C. (2013). Staphylococcus. In: Jawetz, Melnick and Adelberg's Medical Microbiology, Twenty- Sixth Edition. McGraw- Hill, USA, Pp 199 205.

Lancette, G.A. and Tatini, S. R. (1992). Staphylococcus aureus. In: Vanderzant, C., Splittstoesser, D.F., Edition. Compendium of methods for the microbiological examination of foods. Washington, American Public Health Association. P. 533- 550.

Montesinos, I., Salido, E., Delgado, T., Cuervo, M. and Sierra, A. (2002). Epidemiologic genotyping of methicillin- resistant Staphylococcus aureus by pulsed field gel electrophoresis at a University hospital and comparison with antibiotyping and protein $\mathrm{A}$ and coagulase gene polymorphisms. Journal of Clinical Microbiology, 40: 2119- 2125.

Nwankwo, E.O. and Nasiru, M.S. (2011). Antibiotic sensitivity pattern of Staphylococcus aureus from clinical isolates in a tertiary health institution in Kano, Northwestern Nigeria. Pan Africa Medical Journal, 8:4.

Ryan, K.J and Ray, C.G. (2004). Plague and other Bacterial Zoonotic Diseases. In: Sherris Medical Microbiology, An Introduction to Infectious Diseases, Fourth Edition. McGraw-Hill, USA, Pp 481-491.

Silva, W. P., Destro, M. T., Landgraf, M. and Franco, B. D. (2000). Biochemical characteristics of typical and atypical Staphylococcus aureus in mastitic milk and environmental samples of Brazilian dairy farms. Brazilian Journal of Microbiology, 31(2), 103-106.

Smolinski, M.S., Hamburg, M.A., Lederberg, J. (2003). Microbial threats to health: emergence, detection and response. Washington Institute of Medicine, 32.

The World Gazetteer (2007). Archived from the original on $30^{\text {th }}$ September 2007.

\section{How to cite this article:}

Martha Echioda-Ogbole, James A. Yaza, James A. Ameh, Samuel Mailafia, Olatunde H. Olabode, Bridget J. Adah, Godspower R. Okoh and Stella Maduike. 2018. Coagulase - Positive Staphylococci Isolated from Cattle in Maiduguri, Nigeria. Int.J.Curr.Microbiol.App.Sci. 7(05): 1301-1306. doi: https://doi.org/10.20546/ijcmas.2018.705.158 